Grand Valley State University

ScholarWorks@GVSU

$10-2016$

\title{
The Socratic Method: Empirical Assessment of a Psychology Capstone Course
}

Lawrence R. Burns

Grand Valley State University, burnsl@gvsu.edu

Paul L. Stephenson

Grand Valley State University, stephenp@gvsu.edu

Katy Bellamy

Grand Valley State University

Follow this and additional works at: https://scholarworks.gvsu.edu/psy_articles

Part of the Psychology Commons

\section{ScholarWorks Citation}

Burns, Lawrence R.; Stephenson, Paul L.; and Bellamy, Katy, "The Socratic Method: Empirical Assessment of a Psychology Capstone Course" (2016). Peer Reviewed Articles. 56.

https://scholarworks.gvsu.edu/psy_articles/56

This Article is brought to you for free and open access by the Psychology Department at ScholarWorks@GVSU. It has been accepted for inclusion in Peer Reviewed Articles by an authorized administrator of ScholarWorks@GVSU.

For more information, please contact scholarworks@gvsu.edu. 
The Socratic method: Empirical assessment of a Psychology Capstone course

Running Head: TEACHING THE CAPSTONE USING THE SOCRATIC METHOD

Lawrence R. Burns ${ }^{\text {a, }}$,

Paul L. Stephenson ${ }^{b}$

Katy Bellamy ${ }^{a}$

a Department of Psychology, Grand Valley State University

${ }^{\mathrm{b}}$ Department of Statistics, Grand Valley State University

* Corresponding author at: Department of Psychology, Grand Valley State University 1 Campus Drive, Allendale MI 49401, United States

E-mail address: burnsl@gvsu.edu 


\begin{abstract}
Although students make some epistemological progress during college, most graduate without developing meaning-making strategies that reflect an understanding that knowledge is socially constructed (Pizzolato, 2006). Using a pretest-posttest design and a withinsubjects 2 x 2 mixed-design ANOVA, this study reports on empirical findings supportive of the Socratic method of teaching as effective in challenging and changing psychology capstone students' levels of epistemological maturity as measured by the Learning Environment Preferences survey and Perry's (1970) model of intellectual maturity.
\end{abstract}

Keywords: psychology capstone, Socratic method, cognitive complexity index, Learning Environment Preferences, LEP, constructivist 


\section{Introduction}

Many students leave academia without developing meaning-making strategies that reflect an understanding that knowledge is socially constructed (Pizzolato, 2006). In particular, as Cuseo (2007) reports, students need to develop critical thinking skills that can be applied outside of the classroom in real-life situations. This is of international interest (Buehl, 2008) and particular concern for the discipline of psychology as the American Psychology Association's (APA) (2013) guidelines for the teaching of psychology highlight the importance of psychological literacy, while addressing specific goals required of a psychology major including critical and creative thinking and the ability to apply psychological principles to personal, social, and organizational issues. Furthermore, the goals include the need for students to learn how to tolerate ambiguity and respect international diversity and behavior (Zagoria, 2014). However, Dunn et al. (2009) note that institutions in the USA have largely ignored past attempts to implement guidelines in psychology teaching, specifically the inclusion of a capstone course during the final year. Instead, Halpern et al. (2009) report the growing trend of psychology departments to deliver more specialized courses (e.g., cognitive psychology, social psychology) as opposed to providing a solid undergraduate course that delivers key experiences and standards within the psychology discipline.

Outlined extensively by the Association of American Colleges and Universities (Carey, 2013), is the promotion of culminating projects or capstone courses. Capstone course goals are aligned with APA objectives and typically include opportunities for students to integrate, create/synthesize, and apply knowledge (Bangasser, et al., 2016). Encouraging students to question their understanding of the nature of their knowledge in a rigorous, intellectually authentic manner can be transformative (Ashworth, 2004; Formenti, 2015; Goodman, Murphy, \& D’Andrea, 2014; Illeris, 2015). Different instructional approaches may 
achieve equally valid outcomes, but empirical work associated with specific approaches remains limited (Buehl \& Alexander, 2001; ten Dam \& Volman, 2004). The use of a discussion-based format (Nunn, 1996), especially one based on the Socratic method can be highly effective (Bagshaw, 2014; Pihlgren, 2008).

\section{Meaning making through a capstone course}

Bloom's original taxonomy (1956) of learning objectives was revised by Anderson and Krathwohl (2001) resulting in three main categories called analysis, evaluation and creating (also called synthesis). Meaning making is creating; the outcome of which is successfully combining elements to form a coherent or functional whole. It has two fundamental aspects - intellectual maturity and situations that encourage autonomous problem solving (Huber, 2005; Pizzolato, 2006). Clegg (2015), identified five key knowledge practices or forms of meaning making: description, personal reflection and reflexivity, explicitly theoretical, and data-driven. Capstone courses vary in the proportional use of these, but intellectual maturity requires personal reflection and reflexivity — of the instructor and the students (Avalos, 2016; Bangasser, et al., 2016; Bendixen, 2002).

Perry's full learning model (1970) is based on a stage model of intellectual development and encompasses nine stages or positions. Starting with basic duality (in which knowledge is basically right or wrong), it culminates with a sense of personal identity and commitment despite uncertainty or conflicting sources (Thomas, 2008). As Remy (2015) notes, used in tandem, Bloom's taxonomy provides a hierarchical framework of learning objectives and Perry's model offers a degree of insight into how students' epistemological maturity may interact with tasks aimed at particular learning outcomes. Myers (2010, p. 124), summarizes nicely, “...dualist students want to receive information, multiplist students want to learn how to think and contextual relativist students want to exercise their ability to think." An awareness of these differences allows one to anticipate and shape course discussion by 
using questions of increasing ambiguity while moving subtly between the stages identified by Perry (or related theoretical models). Rapaport (2002, 48), by way of a student comment, provides a simple example, "I really enjoyed this course. I had lots of trouble till about $2 / 3$ into the course, 'cause I was looking for answers. Once I realized there were no answers and you had to figure things out for yourself, it became easier." This comment reflects a shift from Perry's dualism to multiplism and accompanying insight. Within psychology a central learning outcome is engaging with the acceptance of uncertainty or ambiguity in meaning.

Metacognition refers to the knowledge of one's cognitive processes and how these can affect one's learning performance (Delahaij \& van Dam, 2016; Muis \& Franco, 2010). Epistemic metacognition seeks to integrate metacognition and developmental epistemology. Current work applies much of Perry's developmental model (and those of a number of other theorists; see also Maggioni, VanSledright, \& Alexander, 2009) by highlighting a useful distinction between the cognitive and affective processes associated with changing one's beliefs and the new [beliefs] themselves (Bendixen, 2002; Hofer, 2002, 2016; Hofer \& Sinatra, 2010; Sinatra, 2016).

Inquiry-based teaching and capstone experiences help students "integrate, apply, and evaluate...diverse findings as well as the psychological perspectives" (Wade, 1997, p. 151). The capstone course is intended to allow an instructor to assess the student's overall collegiate learning experience, and by its very nature is a method of summative evaluation. Capstone course expectations include a display of a mastery of learning and the ability to apply it to new, unusual and integrated project requirements. A primary goal of teaching and outcomes assessment in the capstone course involves presenting the students with authentic challenges connected with knowledge mastery, reasoning proficiency, and professional expectations (Dunlap, 2005; Stiggins, 1997). Reflective questions can make students aware of what they know and what they don't know. These types of questions are key to the 
Socratic method. Thoughtfully challenging capstone student's assumptions based on metacognitive principles is one way of prompting autonomy and mastery by way of meaning making (Ford, Smith, Weissbein, \& Gully, 1998).

\section{Using the Socratic method in a capstone course}

The Socratic method uses enquiry in varying degrees (Furedy \& Furedy, 1982; Pang, 2008). Introducing dissonance by way of follow-up questioning, an instructor can effectively, and respectfully, prompt consideration of changes in Perry's epistemological positions by way of accommodation (Bendixen, 2002; Proulx \& Heine, 2010). Processing various cognitive and affective components of oneself and others, and learning to receive and provide feedback are integral components of the course (Berman, 2007; Biesta, 2013; Paivi, 1998; Richardson, 2013).

According to Jonassen (2002), within this learning environment the teacher acts as a participant-facilitator and is thus able to guide and scaffold the learning process by providing related experiences about which students may not have firsthand knowledge. This includes modeling reasoning and generalization of similar situations. For example, in the 'loss and grief' section of the course many students initially respond that they have not 'lost' anyone, but when the discussion shifts to relationship break-ups, and then circles back to the empirical work (Wortman \& Silver, 1989; Wortman \& Boerner, 2011) students are able to connect affectively with the topic.

\section{Students may often know what they think, but not why}

The weekly selection of primary readings purposely incorporate a diverse range of alternative perspectives and competing world views (e.g., course syllabi here). For example, Cain (2006) on the consequences of parental suicide; Huss and Cwikel (2008) on the use of art as a technique for socially acceptable expressions of distress in Bedouin women; or Hansbury (2004) and his narrative characterizing the cognitive, affective, and behavioral 
experiences of undergoing sexual reassignment from female to male. This is not a "controversial issues" approach, but rather, a "novel viewpoints, never considered before" approach. Thus, the teacher, acting as facilitator, then uses the questions submitted by students to extend into discussions that use to advantage the students' differing perspectives, interpretations, and alternative ways of resolving the divergent vantage points. Wrestling cooperatively with different theoretical and empirical standpoints on a weekly basis introduces a sustained degree of ambiguity and access to Perry's (1970) culminating stage of personal identity (Moore, 2009). In a safe discussion-based setting this type of enquiry and ensuing conversation is intended to prompt an educated commitment to the students' beliefs based on why they reach a particular conclusion.

Course processes are modeled after the Socratic method described by Paul (1995):

This consists in teachers wondering aloud about the meaning and truth of students' responses to questions. The Socratic teacher models a reflective, analytic listener. One that actively pursues clarity of expression. One that actively looks for evidence and reasons. One that actively considers alternative points of view. One that actively tries to reconcile differences of viewpoint. One that actively tries to find out not just what people think but whether they think it is actually so (Paul, 1995, p. 297).

One important goal of this approach is to incorporate relevant guidelines as identified by the APA (2013). In particular, capstone students come to genuinely value the effort required of them to engage in critical thinking (rather than simply being critical), to actively apply the sum of their acquired skills and knowledge and to bring it to bear on authentic contemporary issues (parenting, interpersonal relationships, culture, diversity, etc.). In this way, by inviting thoughtful consideration of complex relevant issues, students are willing to 
tolerate ambiguity while reflecting on their personal and adopted discipline-based ethics and professional values (for examples please see Teaching the Capstone video based on alumni interviews here).

\section{Some questions are better than others}

Key to the Socratic method and an inquiry-based approach to teaching is developing the skillful exchange of questions that respectfully challenge thinking and to promote open discussion (Toledo, 2015). Discussion within the classroom prompts creating/synthesis and promotes the use of higher order aspects of knowledge use as identified by Bloom (1956) and others. As an example, based on the original work by Andrews (1980), explicit fact-based questions (e.g., What was the name of that institution?) yield the fewest subsequent associated number of student statements (NSS), 1.45 (it has only one answer) compared with a focal, invitation to explore a topic (e.g., Can we make any generalizations about the play as a whole, from the nature of the opening lines?), which yields an average number of 5.08 subsequent related student statements. By properly formatting questions the facilitator can model the process of learning itself and using the Socratic method authentically can result in epistemological shifts in students' perceptions of themselves and the world (Asterhan \& Schwarz, 2016; Tredway, 1995). This is precisely the goal of evaluation and creation (synthesis).

While it is the case that various instructional methods may be aligned with these and other APA Guidelines (2013), the current study seeks to examine whether Perry's (1970) framework of cognitive development can effectively assess particular outcomes associated with the Socratic method. Does this instructional approach prompt meaningful epistemological shifts in student's knowledge structures compared to traditional lecture-only based courses within an academic semester? To examine this question difference scores were 
calculated (Time 2 score minus Time 1 score). The hypothesis is that by utilizing a pre-post design and Moore's (1989) Learning Environment Preference survey (LEP) to assess Perry’s model (1970) of epistemological maturity within sections of a psychology capstone course based on Socratic principles, demonstrable epistemological shifts should be evident in the students' perspectives. Likewise, following the same pre-post design in a comparison group of lecture-only participants, no differences in epistemological perspective are expected.

\section{Method}

The capstone course described in this report is predicated on the constructivist learning environment model (CLE) outlined by Jonassen (2002; see also ten Dam \& Volman, 2004). The goal of this model is to foster a classroom atmosphere where students are actively involved in dealing with messy, ill-structured real-life topics. Using a graduate-style seminar approach, weekly readings are selected to allow students to use what they have learned but also to challenge that knowledge along with unexplored assumptions acquired along each student's particular path through the curriculum as a whole. The course is fully discussionbased and the focus of learning involves questions which the students are required to submit. These are shared with the class in a fully anonymous manner. Thus, student's questions are discussed openly in class, but in an entirely safe way.

\subsection{Participants}

\section{Lecture-only (comparison) group}

Participants were approximately 90\% psychology undergraduate students, 116 (87 women, 15 male, and 14 not provided) enrolled in two different upper-level lecture-only courses (two separate class sections of each) at a large Midwestern comprehensive university. Upper-level psychology courses often involve the study of theories and methods, and developing an understanding of the applications and limitations of those theories. As a result, students generally take upper-division courses in their junior and senior years. A semester is 
15 weeks in duration. The age of students ranged from 19 to 41 years $(M=22.2, S D=3.1)$. While course material differed for the two courses, they were taught by the same instructor and offered a very similar structure (course grades were based on four multiple-choice exams and course writing exercises formed roughly the same proportion of students' grades between the two courses). Both were upper-level core classes (Psy-303 Psychopathology and Psy-420 Theories of Personality). Both classes involve conceptual work and are composed of predominantly junior/senior psychology undergraduate students. These courses aim past simple content and attempt to encourage students to avoid rote memorization and toward a deeper understanding of the material. Informed consent regarding completion of the LEP survey was obtained, and participation was entirely voluntary.

\section{Socratic method group}

Participants were 135 (116 women, 17 male, and 2 not provided) undergraduate students enrolled across six (separate) capstone classes (taught by the same instructor) at a large Midwestern comprehensive university. Each class had an average size of about 22 students. A semester is 15 weeks in duration. The age of students ranged from 20 to 55 years $(M=23.1, S D=5.6)$. All students enrolled in the capstone course except one were seniors. Informed consent regarding completion of the LEP survey was obtained and participation was entirely voluntary. Of an initial 150 students, 16 students did not complete the study (ten dropped the course and six failed to complete the Time 2 portion); differences between completers and non-completers on the measure at Time 1 were not significant, $F(1,165)=$ $1.28, p=.73$. No other demographic data were collected.

\subsection{Procedure}

Data collection followed the same procedure across all semesters. Students completed the survey twice, initially during the first week of the semester (Time 1) and then a second time in the final week of the semester (Time 2) using a within-subjects pretest- 
posttest design. An ANOVA found no significant differences between the students by semester based on total credits completed or cumulative GPA, thus data from all three semesters were combined.

\subsection{Measures}

The Learning Environment Preferences survey (Moore, 1989; LEP) is designed to be used with student populations, primarily in colleges and universities. It can be used to measure patterns of longitudinal intellectual development across various subgroups of students or for pre-post evaluations of specific courses or groups of courses. It consists of 65 items subdivided into five domains (course content, the roles of instructors and peers, classroom atmosphere and activities, and course evaluation) related to approaches to learning. Adequate validity and reliability has been reported (Moore, 1989; 2000). The coefficient alpha ranges from .72 to .84 for the four levels examined (Moore, 2000). The measure assesses differences in intellectual and cognitive development in college students based on Perry's (1970) model $^{1}$, specifically Positions 2 through 5. Respondents rate each item on a four-point Likert-style self-report scale according to how significant they find that item in relation to their perception of the ideal learning environment. Respondents then rank the three most significant items to them personally from each of the five domains. Items range from simpler to more complex across each of the domains. For example, "Teach me all the facts and information I am supposed to learn," "Include straightforward, not "tricky," tests, covering only what has been taught and nothing else," "Challenge students to present their own ideas, argue with positions taken, and demand evidence for their beliefs," or "Allow

${ }^{1}$ Perry's model has 9 positions (i.e., stages), but according to Moore (2000), the LEP selectively assesses positions $2-5$ because position 1 has not been empirically verified and research has suggested that cognitive-structural change does not extend beyond position 5 . A summary score, the Cognitive Complexity Index (CCI), indicates a respondent's degree of intellectual and cognitive development. Sample CCI scores in this study ranged from 213 to 465 and did not evidence a restriction in range. 
students to demonstrate that they can think on their own and make connections not made in class." A summative value, the Cognitive Complexity Index (CCI), is the primary score of the LEP and represents a respondent's epistemological position. The CCI scale of intellectual development has a range of 200 (Perry Position 2) to 500 (Perry Position 5). The Cognitive Complexity Index (CCI) showed a test-retest correlation of .89 (Moore, 2000).

\section{Results}

The means and standard deviations for the CCI scores of each group are presented in Table 1.

Insert Table 1 about here

Comparison group

In an effort to ascertain if the two comparison courses could be combined, a twosample independent t-test was conducted to examine if a difference was present in the mean difference CCI score between Time 1 and Time 2 between student participants in the two lecture-only courses (four sections total; two sections of each course). The mean difference in CCI scores from Time 1 to Time 2 between the comparison sections were not significant, $t(114)=-0.129, p=.898$. This indicates that there is insufficient evidence to conclude that a significant difference exists in the mean difference in CCI scores from Time 1 to Time 2. Given the lack of differences by cumulative credits, grade point average, or changes in the CCI scores between the students in the comparison sections, and that the preponderance of students in the classes were psychology students, the course sections were combined to create a single comparison group.

\section{Main Study}

Now a 2 x 2 mixed-design ANOVA will be used to ascertain if differences exist in mean CCI scores by group and time. In our study, CCI is measured twice for each subject, 
once before the semester and again at the conclusion of the semester. As a result, we have a mix of one between-subjects factor (group) and one within-subjects factor (time). The results of mixed ANOVA (shown on Table 2) indicate that a significant interaction exists between Insert Table 2 about here

group and time, $F(1,248)=7.84, p=0.006$. Therefore, there is sufficient evidence to conclude that significant differences exist in the mean CCI scores due to interaction between group (Socratic method versus lecture-only) and time (before and after semester). Figure 1 displays Insert Figure 1 about here

the mean CCI plot by group and time. Hypothesis tests on the contrasts were used to examine if a difference was present in the mean CCI score before and after the semester for both the students in the Socratic method group and the lecture-only group. The difference in mean CCI scores was not significant for the lecture-only group $(F(1,247)=1.72, p=0.19)$, and the difference in mean CCI scores was significant for the Socratic method group $(F(1,249)=$ $30.26, p=<0.0001)$. This indicates that only the Socratic method group demonstrates sufficient evidence to conclude that a significant difference exists in the mean CCI scores before and after the semester. A 95\% confidence interval for the mean difference in CCI scores between Time 1 and Time 2 for the Socratic method group is $(10.18,28.26)$, and a 95\% confidence interval for the mean difference in CCI scores for the lecture-only group is ($4.77,14.56)$. In conclusion, examination of the confidence intervals for the mean differences reveals that the Socratic method group reported increased cognitive complexity and the lecture-only group failed to demonstrate improvement (because the confidence interval did not include 0).

\section{Discussion}

The results of this study demonstrated a significant shift in students' epistemological beliefs, specifically beliefs that would normally be resistant to change (Schommer-Aikins, 
2004; Swann, 1997; Sweeny \& Miller, 2012). By using a capstone course based entirely upon the Socratic teaching method, psychology students were able to demonstrate the ability to tolerate ambiguity within novel meaning-making processes. This included concomitant challenges to their preconceived beliefs, but with ample scaffolding and thorough discussion.

The LEP provides a theoretically useful way to assess cognitive development in college and university students. In each semester capstone student CCI scores started, roughly, at the transition between Perry positions 3 and 4, and at the conclusion of the course 15 weeks later, had shifted to the initial stages of position 4 (Moore, 1989; Hassaskhah, Sepahi, \& Azarnava, 2012). Shifting from the dualistic view of position 2 (with a belief that there should only be one right answer), to a position 3 view that there may be multiple right answers is a big step. Between position 3 and 4 students have typically accepted the likelihood of multiple answers as correct but efforts to encourage consideration of some answers as a better fit for the facts than others can be met with frustration. This is where conversations in class are very beneficial. Students can often "hear" other students, even when views differ, if someone with a bit more insight explains why they have come to a particular conclusion. When the instructor is able to pose Socratic questions that encourage students to reflect in this way and then share their thoughts, scaffolding as such can thus be subtle and helpful. As a result, this type of capstone course can motivate peer-to-peer modeling, allaying anxiety and encouraging students to consider new perspectives (Asterhan \& Schwartz, 2016; Bendixen, 2002). Current findings suggest that for teachers of Psychology courses whose goal is to have students change the way they understand the nature of their knowledge, the Learning Environment Preferences scale captures some of these changes with sufficient sensitivity.

Finding that mean CCI scores did improve in the Socratic method group demonstrates that a single 15 -week semester is an adequate interval of time for students in a capstone 
course to evidence significant improvement. The constructivist model posits one type of learning as a change in identity. Scaffolding incorporates the premise of Vygotsky's zone of proximal development. This serves as an effective way to provide an appropriate degree of challenge and personal risk-taking within a context of sufficient perceived personal safety when faced with increasing ambiguity (Asterhan \& Schwartz, 2016). These principles are central to the effective use of the Socratic method and account for much of the pedagogical value embedded in the dialectic approach.

\section{Limitations/Future Research}

There are limitations to this study that should inform future research. For example, the data for this study lacked external comparison, as all sections were taught by the same instructor. It may be the case that the instructor is more effective in discussion-based versus lecture-only courses. While the comparison courses were not capstone courses, they were upper-level core courses for the Psychology major, including predominantly junior and senior level psychology students. As such, one of the goals in the upper-level courses is, per Elby (2001, p. S54), "helping students understand the importance of consistency and coherence, and the difference between rote memorization and deeper understanding." By the same token, questions on the Psychology subject test of the Graduate Record Examination are derived from material associated with these core courses. Thus, full coverage of text material is expected and these courses may default to content and focusing on key words, thus limiting the use of metacognitive strategies, meaning making, and epistemological development. Future work using different comparison groups would be useful.

Additionally, the study samples contained a larger proportion of women. Psychology undergraduate courses tend to have a predominance of female applicants, so future research should provide a comparison of this method across psychology courses and, if possible, examine whether gender differences are influenced by this style of teaching. Future work 
examining the degree of change associated with the Socratic method in other types of discussion-based classes and other fields of study might prove beneficial. Present findings, in conjunction with recent work in the field suggest further investigation of the role of epistemic doubt and its resolution are important. A better understanding of underlying metacognitive processes associated with Socratic methods would prove useful (Bagshaw, 2014; Dinsmore \& Alexander, 2016). In addition, the researchers have interest in extending the duration of this study to ascertain whether the improvement in epistemological perspective is retained over time.

\section{Conclusions}

Despite these limitations the current findings suggest that the Socratic teaching method can enable students to challenge and reconcile different points of view (Paul, 1995) and at the same time allow the teacher to reliably assess valid student learning outcomes across the curriculum. Future research aimed at specific capstone assignments that might track bigger changes in specific domain scores on the LEP as well as the CCI composite scores could lend itself to a rich discussion on how best to assess particular course components, not just in capstone courses, but courses in general.

Assessment within the capstone offers a unique vantage point on the science of psychology as an evolving discipline best understood from an array of differing perspectives (Mentkowski, Diez, Lieberman, Pointer, Rauschenberger, \& Abromeit, 2016). This study proposes using the Learning Environment Preferences scale as one approach to assessing course goals as identified by the APA and other professional bodies (e.g., in Europe and Australia). If debates about the best way to teach could be based on reliable and valid assessments of desired outcomes, it might do a lot to improve teaching. The thoughtful examination of passionate but empirically unverified claims about the efficacy of different teaching strategies has steadily increased in importance. The Socratic method can be 
meaningfully assessed, and is aligned with APA (2013) goals - consistently challenging faculty and students to reflect deeply, and to strive to ask ever more insightful questions about cognition, behavior, and experience (McGovern et al., 1991; Kazanjian \& Choi, 2016). 
Integrity of Research and Reporting

Declaration of Conflict of Interest

The authors declare that they have no conflict of interest with respect to the authorship, research, and/or publication of this article. 


\section{References}

American Psychological Association (2013). APA guidelines for the undergraduate psychology major Version 2.0. Washington, DC: Author. Retrieved from http://www.apa.org/ed/precollege/about/psymajor-guidelines.pdf

Anderson, L. W. \& Krathwohl, D. R. (Eds.), (2001). A taxonomy for learning, teaching and assessing: A revision of Bloom's Taxonomy of educational objectives. New York: Longman.

Andrews, J. D. (1980). The verbal structure of teacher questions: Its impact on class discussion. POD Quarterly, 2, 130-163.

Ashworth, P. (2004). Understanding as the transformation of what is already known. Teaching in Higher Education, 9(2), 147-158.

Asterhan, C. S. C. \& Schwarz, B. B. (2016). Argumentation for learning: Well-trodden paths and unexplored territories. Educational Psychologist, 51(2), 164-187.

Avalos, B. (2016). Learning from research on beginning teachers. In J. Loughram and M. L. Hamilton (Eds.), International handbook of teacher education (pp. 487-522). Singapore: Springer.

Bagshaw, M. (2014). Reflections on a Socratic approach to engagement. Industrial and Commercial Training, 46(7), 357-363.

Bangasser, D. A., Rozensky, R. H., Fowler, G. A., Kraha, A., Lopez, A. A., O’Connor, M., Worrell, F. C., \& Kaslow, N. J. (2016). Psychology's core knowledge, scientific subfields, and health service specialization: Preparing a competent workforce-Recommendations from the Opening Doors Summit. Training and Education in Professional Psychology, 10(2), 84-92.

Bendixen, L. D. (2002). A process model of epistemic belief change. In B. K. Hofer \& P. R. Pintrich (Eds.), Personal epistemology: The psychology of beliefs about knowledge and knowing (pp. 210-225). Mahwah, NJ: Lawrence Erlbaum.

Berman, J. (2007). Dying to teach. State University of New York Press: Albany, NY.

Biesta, G. (2013). The beautiful risk of education. Paradigm Publishers: Boulder, CO.

Bloom, B. (1956). Taxonomy of educational objectives. New York: McKay. 
Buehl, M. M. (2008). Assessing the multidimensionality of students' epistemic beliefs across diverse cultures. In M. S. Khine (Ed.), Knowing, knowledge, and beliefs: Epistemological studies across diverse cultures (pp. 65-112). Dordrecht, Netherlands: Springer.

Buehl, M. M. \& Alexander, P. A. (2001). Beliefs about academic knowledge. Educational Psychology Review, 13(4), 385-418.

Burns, L. R., "Teaching the Psychology Capstone (video)" (2015). Conference Materials. Retrieved from http://scholarworks.gvsu.edu/psy_conference/2/

Cain, A. C. (2006). Parent suicide: Pathways of effects into the third generation. Psychiatry: Interpersonal and Biological Processes, 69, 204-227.

Carey, S. J. (Ed.) (2013). Capstones and integrative learning. Peer Review, 15(4).

Clegg, S. (2015). Adventures in meaning making: Teaching in Higher Education 2005-2013. Teaching in Higher Education, 20(4), 373-387.

Cuseo, J. (2007). The empirical case against large class size: Adverse effects on the teaching, learning, and retention of first-year-students. Journal of Faculty Development, 21(1), 5-22.

Delahaij, R. \& van Dam, K. (2016). Coping style development: The role of learning goal orientation and metacognitive awareness. Personality and Individual Differences, 92, 57-62.

Dinsmore, D. L. \& Alexander, P. A. (2016). A multidimensional investigation of deep-level and surface-level processing. The Journal of Experimental Education, 84(2), 213-244.

Dunlap, J. C. (2005). Problem-based learning and self-efficacy: How a capstone course prepares students for a profession. Educational Technology Research and Development, 53(1), 65-85.

Dunn, D. S., Brewer, C. L., Cautin, R. L., Gurung, R. A. R., Keith, K. D., McGregor, L. N., Nida, S. A., Puccio, P. \& Voigt, M. J. (2009). The undergraduate psychology curriculum: Call for a Core. In D. F. Halpern (Ed.), Undergraduate Education in Psychology, American Psychology Association: Washington.

Elby, A. (2001). Helping physics students learn how to learn. American Journal of Physics, 69(S1), S54-S64. 
Ford, J. K., Smith, E. M., Weissbein, D. A., Gully, S. M., \& Salas, E. (1998). Relationships of goal orientation, metacognitive activity, and practice strategies with learning outcomes and transfer. Journal of Applied Psychology, 82(2), 218-233.

Formenti, L. (2015). A dialogical reframing. Journal of Transformative Education, 12(2), 123-133.

Furedy, J. J., \& Furedy, C. P. (1982). Socratic and Sophistic Strains in the Teaching of

Undergraduate Psychology: Some Implicit Conflicts made Explicit. Teaching of Psychology, 9, 14-20.

Goodman, S. B., Murphy, K. B., \& D’Andrea, M. L. (2014). Discussion dilemmas: an analysis of beliefs and ideals in the undergraduate seminar. International Journal of Qualitative Studies in Education, 27(1), 1-22.

Halpern, D. F., Anton, B., Beins, B. C., Bernstien, D. J., Blair-Broeker, C. T., Brewer, C. L., Buskist, W., Casad, B. J., Dixon Jr., W. E., Harper, Y. Y., Hailstorks, R., Kite, M. E., Puccio, P. \& Rocheleau, C.A. (2009). Principles for quality undergraduate education in psychology. In D. F. Halpern (Ed.), Undergraduate Education in Psychology, American Psychology Association: Washington.

Hansbury, G. (2004). Sexual TNT: A transman tells the truth about testosterone. Journal of Gay and Lesbian Psychotherapy, 8(1), 7-18.

Hassaskhah, J., Sepahi, D., \& Azarnava, H. (2012). The role of BA curriculum in the intellectual development of English Major students. ESP Maritime English Journal, 1(3), 63-81.

Hofer, B. K. (2002). Personal epistemology as a psychological and educational construct: An introduction. In B. K. Hofer \& P. R. Pintrich (Eds.), Personal epistemology: The psychology of beliefs about knowledge and knowing (pp. 3-14). Mahwah, NJ:

Lawrence Erlbaum.

Hofer, B. K. (2016). Epistemic cognition as a psychological construct: Advancements and challenges. In J. A. Greene, W. A., Sandoval, \& I. Bråten, (Eds.). Handbook of epistemic cognition (pp. 1938). NY: Routledge. 
Hofer, B. K. \& Sinatra, G. M. (2010). Epistemology, metacognition, and self-regulation: musings on an emerging field. Metacognition Learning, 5, 113-120.

Huber, F. (2005). Subjective probabilities as basis for scientific reasoning? British Journal for the Philosophy of Science, 56(1), 101-116.

Huss, E. \& Cwikel, J. (2008). Shifting pain from the body to society: embodied drawings of impoverished single Bedouin mothers. Archives of Women's Mental Health, 11(2), 137-147.

Illeris, K. (2015). Transformative learning and identity. Journal of Transformative Education, 12(2), 148-163.

Jonassen, D. H. (2002). Engaging and supporting problem solving in online learning. Quarterly Review of Distance Education, 3(1), 1-13.

Kazanjian, C. J. \& Choi, S. (2016). The person over standardisation: a humanistic framework for teacher learning in diverse school-based contexts, Pedagogy, Culture \& Society, 24(2), 255-267.

Maggioni, L., VanSledright, B., \& Alexander, P. A. (2009). Walking on the borders: A measure of epistemic cognition in history. The Journal of Experimental Education, 77(3), 187-213.

McGovern, T. V., Furrumoto, L., Halpern, D. F., Kimble, G. A. \& McKeachie, W. J. (1991). Liberal education, study in depth, and the arts and sciences major-psychology. American Psychologist, $46,598-605$.

Mentkowski, M., Diez, M. E., Lieberman, D., Pointer, D., Rauschenberger, M., \& Abromeit, J. (2016). Conceptual elements for performance assessment for faculty and student learning. In P. F. Wimmers and M. Mentkowski, (Eds.), Assessing competence in professional performance across disciplines and professions, innovation and change professional education (pp. 11-38). Switzerland: Springer.

Moore, W. S. (1989). The Learning Environment Preferences: Exploring the construct validity of an objective measure of the Perry Scheme of intellectual development. Journal of College Student Development, 30, 504-514.

Moore, W. S. (2000). The learning environment preferences: An instrument manual, Center for the Study of Intellectual Development; Olympia, Washington. 
Moore, W. S. (2009), Understanding learning in a postmodern world: Reconsidering the Perry scheme of intellectual and ethical development. In B. K. Hofer \& P. R. Pintrich (Eds.) Personal Epistemology: The Psychology of Beliefs about Knowledge and Knowing (pp. 17-36). New York: Routledge.

Muis, K. R. \& Franco, G. M. (2010). Epistemic profiles and metacognition: support for the consistency hypothesis. Metacognition Learning, 5, 27-45.

Myers, S. A. (2010). Using the Perry scheme to explore student classroom participation. Communication Research Reports, 27(2), 123-130.

Nunn, C. (1996). Discussion in the college classroom. Journal of Higher Education, 67(3), 243-266.

Paivi, T. (1998). Traditional studying for examination versus constructivist learning tasks: Do learning outcomes differ? Studies in Higher Education, 23(2), 173-189.

Pang, K. (2008). Sophist or Socratic teaching methods in fostering learning in US graduate education. International Journal of Learning, 15(6), 197-201.

Paul, R. (1995). Critical Thinking: How to Prepare Students for a Rapidly Changing World. Santa Rosa, CA: Foundation for Critical Thinking.

Perry, W. G. (1970). Forms of Intellectual and Ethical Development in the College Years: A Scheme. San Francisco, CA: Jossey-Bass.

Pihlgren, A. S. (2008). Socrates in the classroom. Stockholm, Sweden: Elanders Sverige AB.

Pizzolato, J. E. (2006). Complex partnerships Self-authorship and provocative academic-advising practices. NACADA Journal, 26(1), 32-45.

Proulx, T. \& Heine, S. J. (2010). The frog in Kierkegaard's beer: Finding meaning in the threat compensation literature. Social and Personality Psychology Compass, 4(10), 889-905.

Rapaport, W. J. (2002). The Perry scheme of intellectual development: Approaches to successful learning [PowerPoint slides]. Retrieved from http://www.cse.buffalo.edu/ rapaport

Remy, J. (2015). Combatting dualistic thinking with problem-based learning in my classroom. Retrieved from http://www.usma.edu/cfe/Literature/Remy_16.pdf 
Richardson, J. T. E. (2013). Epistemological development in higher education. Educational Research Review, 9, 191-206.

Schommer-Aikins, M. (2004). Explaining the epistemological belief system: Introducing the embedded systemic model and coordinated research approach. Educational Psychologist, 39(1), $19-29$.

Sinatra, G. M. (2016) Thoughts on knowledge about thinking about knowledge. In J. A. Greene, W. A., Sandoval, \& I. Bråten, (Eds.), Handbook of epistemic cognition (pp. 479-492). NY: Routledge.

Stiggins, R.J. (1997). Student-Centered Classroom Assessment, Second Edition. Upper Saddle River, NJ: Prentice Hall.

Swann, W. B. (1997). The trouble with change: Self-verification and allegiance to the self. Psychological Science, 8(3), 177-180.

Sweeny, K. \& Miller, W. (2012). Predictors of information avoidance: When does ignorance seem most blissful? Self and Identity, 11, 185-201.

Ten Dam, G. \& Volman, M. (2004). Critical thinking as a citizen competence: Teaching strategies. Learning and Instruction, 14, 359-379.

Thomas, J. A. (2008). Reviving Perry: An analysis of epistemological change by gender and ethnicity among gifted high school students. Gifted Child Quarterly, 52(1), 87-98.

Toledo, C. A. (2015). Dog bite reflections-Socratic questioning revisited. International Journal of Teaching and Learning in Higher Education, 27(2), 275-279.

Tredway, L. (1995). Socratic seminars: Engaging students in intellectual discourse. Educational Leadership, 53, 26-29.

Wade, C. E. (1997). On thinking critically about introductory psychology. In R. J. Sternberg (Ed.), Teaching introductory psychology: Survival tips from the experts (pp. 151-162). Washington, DC, US: American Psychological Association, xi, 193 pp. doi: 10.1037/10228-010 
Wortman, C. B. \& Boerner, K. (2011). Beyond the myths of coping with loss; Prevailing assumptions versus scientific evidence. In H. S. Friedman (Ed). The Oxford Handbook of Health Psychology. (pp. 438-476). New York, NY: Oxford University Press.

Wortman, C. B. \& Silver, R. C. (1989). The myths of coping with loss. Journal of Consulting and Clinical Psychology, 57, 349-357.

Zagoria, I. (2014). Constructing meaning from the unfamiliar: Implications for critical intercultural education. In K. Dunworth and G. Zhang (Eds.), Critical Perspectives on Language Education, Australia and the Asia Pacific, Switzerland: Springer International Publishing. 
Table 1

Descriptive Statistics

Lecture-only (comparison) Socratic method

Mean $(S D)$

CCI Time $1330.3(52.9)$

CCI Time $2335.2(54.2)$

$356.1(45.2)$

$376.5(42.1)$

Note. CCI = Cognitive Complexity Index.

Lecture-only (comparison) group $N=116$; Socratic method group $N=135$.

Table 2

$2 \times 2$ Mixed ANOVA (CCI between groups and Time within-subjects)

\begin{tabular}{lccll}
\hline Source & DF & DF & F Ratio & Prob $>$ F \\
& Denominator & & & \\
CCI Group & 1 & 243.7 & 33.4886 & $<.0001$ \\
Time Pre-Post & 1 & 248.7 & 22.2263 & $<.0001$ \\
CCI*Time & 1 & 248.7 & 7.8404 & 0.0055
\end{tabular}

Note. $\mathrm{CCI}=$ Cognitive Complexity Index. Time 1 to Time $2=15$ weeks. 


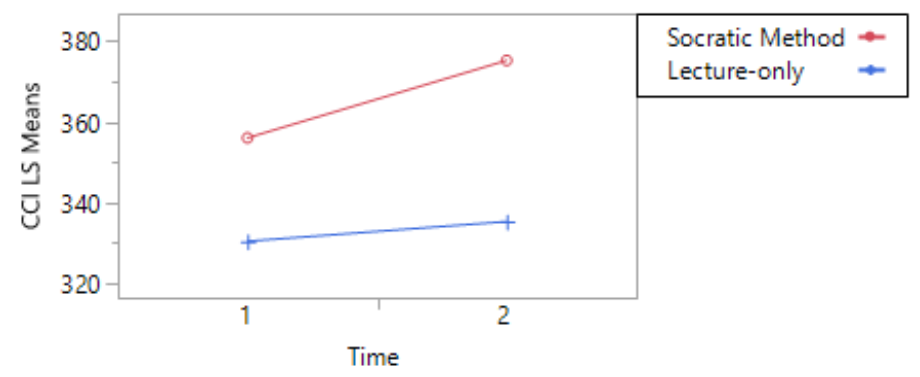

Figure 1 - Socratic method versus Lecture-only groups

CCI scores analyzed using 2x2 Mixed ANOVA (by group and time)

Note. $\mathrm{CCI}=$ Cognitive Complexity Index 